\title{
Transforming a Traditional School Counseling Graduate Program to Distance Learning: the Student Experience
}

\author{
A. Hallford \\ University of Central Arkansas
}

\begin{abstract}
This study used a qualitative descriptive approach to explore student experiences in the process of converting a traditional classroom graduate program to an online distance learning program. The study participants are graduate students enrolled in a school counseling program that is transitioning from the traditional face to face setting to online distance learning. Open-ended questions were administered using the discussion section of Blackboard to students enrolled in an online school counseling course. Inductive content analysis was used until all data had been systematically coded, analyzed, and data saturation achieved. This process was followed by the development of patterns and themes. Findings: Analysis of the qualitative data resulted in a description of the students' view and learning experiences in online course delivery including the strengths and weaknesses. Conclusions: Overall, the strengths of online delivery outweigh the weaknesses. There is a need for improvement in technology systems, and the personal interaction in online learning. Clinical Relevance: This study is relevant because there is not enough research exploring the learning experiences of graduate students in an online school counseling program.
\end{abstract}

Keywords Online Learning, Online Transition, Distance Learning, Counselor Education, Graduate Education, School Counseling

\section{Transforming a Traditional School Counseling Graduate Program to Distance Learning: The Student Experience}

The acquisition and retention of students is highly pertinent to online distance learning (Phillips, Hawkins, Lunsford \& Sinclair-Pearson, 2004). In these challenging times, technology is also shaping the future of education with the growth of distance learning programs. As higher education institutions struggle to meet the growing demand for education from non-traditional students, many are turning to hybrid and online courses (Mansour \& Davison, 2007).

The current evolutionary changes in educational technology and pedagogy will be seen in the future as revolutionary changes in the nature of higher education as a process and as an institution (Hitz \& Turoff, 2005). These formats include: synchronous, asynchronous, online, two way audio and video, video streamed, pod casting, and various combinations of these, otherwise known as hybrid (Turner \& Reed,

* Corresponding author:

ahallford@uca.edu (A. Hallford)

Published online at http://journal.sapub.org/edu

Copyright (C) 2012 Scientific \& Academic Publishing. All Rights Reserved
2006).Unfortunately, there is a lack of evidence demonstrating improved learning experiences in online educationover the traditional classroom instruction.

Background

The courses in this study incorporated both synchronous and asynchronous course communication. Classes were held in the same manner as traditional classes, meeting the same evening at the same time every week, with the exception that students attended class from a computer offsite, usually from their home or workplace, depending on their technology resources. Learner and support services have been offered through orientation classes guiding students through the process, as well as instructional technology support with tutorials from the university sponsored website, a 24 hour help desk resource by internet and telephone, and email or telephone communication between the student and instructor.

The instruction format included independent reading and research along with required projects throughout the course. Students received credit for submitting work, participating in class, evaluating their schools based upon school counseling criteria and standards, posting to the discussion board, and presenting their findings to the class. The class time was devoted to summary presentations of the required reading and resources, student discussions, student questions, and student presentations. Assessments were reflective papers 
for each of the three learning units along with a final project.

\section{Research Aims with Research Questions}

The research proposal's aim was to describe experiences of graduate students enrolled in an online school counseling program in order to obtain a better understanding of the student perspective in learning online. The questions this project addressed were:

1) What was the process like to change from face to face to online instruction?

2) What are the strengths and weaknesses of face to face, hybrid, and online learning?

3) What changes would you make to improve course offerings?

4) Would you recommend this program to others?

\section{Methods}

\subsection{Study Design}

A qualitative, descriptive design was used to explore the experiences of graduate students enrolled in an online learning graduate program. Qualitative descriptive inquiry was chosen because the researcher desired to describe the phenomena of online learning from the everyday experiences of students.

\subsection{Sample and Setting}

Participants for this research were graduate students enrolled in a school counseling program. All 19 students enrolled in a school counseling course were asked to participate in the study. One of the 19 participants is male, four of the 18 females are African American. Ages ranged from 23 years of age to 57 years of age. All participants were residents of the state of Arkansas and licensed teachers. Teaching experience ranged from two to 30 years.

\subsection{Data Collection}

Recruitment of participants for the research followed by data collection occurred in the 2011 academic spring semester after the institutional review process (IRB) at the University of Central Arkansas was completed and final approval obtained. Potential participants were notified via Blackboard communication that explained the study and provided contact information for the researcher.

\section{Data Analysis}

\subsection{Qualitative Content Analysis}

An inductive content analysis was the method of data analysis for this study. Data were systematically and thoroughly analyzed. Each answer was put into a table and coded.
The survey answers were analyzed for words or phrases with the same central meaning in order to identify meaning units. Codes were used to label each condensed meaning unit. Categories were grouped into patterns with the final development of overarching themes that were inclusive of all methods of data collection (Graneheim \& Lundman, 2004).

\section{Findings}

Three themes were identified during the data analyses that reflect the participant's perceptions of online learning. The themes are creating an environment for learning, the unique needs of the school counseling profession, and creating a virtual classroom.

Theme I: Creating an Environment for Learning

A professional educator's perspective of their learning experience is information that can improve online delivery practices and offerings. Finding what provided meaningful learning experiences for these students may contribute to the field of online delivery.

1. Convenience

Especially for working students and students with families, it's more comfortable to attend class from home. Students say they can attend while sick, while their family members are sick, and can attend more often. Online courses are easier because they are less costly, are less dangerous, involve less time traveling, and provide students more time at home with the family and to study. One student reports, "I am able to change clothes, log into class, spread out my materials, sit in the floor or at a desk; and grab a bite to eat, wall while listening, interacting and learning." Another student comments that online learning provides convenience without sacrificing quality and corresponds well with a working student's schedule.

2. The Learning Experience

Students have learned many new things in this format. They report gaining knowledge and applying it to their education careers. They refer to online delivery as an enhanced learning environment that have features in Blackboard and Centra that are absent in the traditional classroom. The students value working at their own pace, working independently, and working ahead. One student wrote, "I learn more, as do my students, when I research, write, and reflect, than I do when I study and cram for facts. I comprehend more this way."

3. Professional Goals

Online education has opened doors for students who would not be able to attend a traditional program due to their remote locations in the state. Students state that they would not be able to pursue their goal of becoming a school counselor if it weren't for the online delivery of this program. Another student wrote that they will be able to apply the knowledge they have learned to their future career.

Theme II: The Unique Needs of the School Counseling Profession

School counselors use their interpersonal skills to read 
situations such as visual cues, body language, facial expressions, and comments. Face to face interaction is an important element of a school counselor' and educators' professional development. They need to make a connection. They need to see the other faces. They need to form friendships and helping relationships.

1. Overcoming less interpersonal interaction

Even though students felt that there was less personal interaction online, students said that the professors are very approachable, guided and use interactive teaching styles. Students also felt that they have gotten to know the other students and meet and form friendships. One student said, "I made a connection online just as we would have if we had met together. I was still able to meet people and form friendships because of discussions about our class work as well as discussions on a personal level before and after class."

\section{Collaboration and the helping relationship}

Students have overcome the difference in online interaction is by getting together outside of class to work or study, having their fellow students' cell phone numbers and email addresses to contact, and by using the text box in the Centra program to give encouragement and comments that encourage one another.

3. How we can provide more personal interaction and visual cues

Class meetings online need to provide more opportunities for feedback and questions from the students. This could be accomplished by giving break time within the class meeting for personal interaction. The use of the textbox should be promoted to students to use. Many times conversations are conducted around the lecture between students that are unrelated to what is going on in the class, and this should be allowed and encouraged to build learning communities. Upgrading technology requirements to allow students to see the other student's faces is one suggestion for filling the void of interpersonal connection lost with online learning communities.

\section{Theme III: Creating a Virtual Classroom}

Students' expressed their classroom experiences as being an enhanced classroom or virtual classroom with similarities in content delivery, collaboration, and discussion. This is considered the highest form of appraisal for the professor. But, as online and face to face instruction are not exactly the same, there is room for creative license in creating new learning experiences for the students that may surpass what exists in the traditional classroom.

\section{Transition to Technology}

Students reflected that the transition to online technology was relatively easy. Most students felt comfortable with computers and technology. Another student noted that this was not the first online course taken, but this experience is a better learning experience. There is a lack of control over tardiness and attendance when there are technical challenges beyond the student's control. One student reported a problem with an online assessment, but the professor corrected the problem. Another student reported that she could not access the program from her home computer, but was able to use her computer at work to attend class.

\section{Acquiring the Skill}

Students participate in an orientation prior to the beginning of the semester that prepared them to attend class successfully. Students also were required to purchase headsets with a microphone. One student commented that online course work required a different skill set than a traditional classroom. From the instructor's point of view, teachers as students have always been high achievers. Transitioning to online was more challenging for the older, experienced teachers, putting them at more of a disadvantage due to holding fewer skills than the younger students.

3. Improvement

The technology systems could be improved to offer interactive webcams which show the other students during synchronous class time. The signal could be improved to allow for more technology to be delivered to remote areas that are challenged by the mountains. The technology department could provide more immediate assistance during online class time, so students do not have to wait and miss part of class. The interaction technology could be enhanced to allow for more communication in addition to hand raising, applause, laughing, green check marks and red X's.

\section{Discussion}

This qualitative descriptive study of graduate students' enrolled in an online program explored their learning experiences. The students in this study brought to light the learning needs and experiences of practicing education professionals. The change from traditional classroom delivery to online delivery was fairly easy for most students, but not all. These teachers as students are attempting to learn in a new way. The lessons delivered to the students online play a big role in learner satisfaction. Lesson plans and improvements in technology features can address these issues.

\section{Limitations}

The limitations of this study involve the purposeful sample of students enrolled in an online school counseling course. The students have invested time and money into their prospective career and may be inhibited to be totally honest with the researcher, who is also their advisor and instructor. Due to this aspect, students were asked to answer the questions once in the discussion section Blackboard, and the response rate was $50 \%$. A larger sample size would be more helpful in drawing conclusions.

\section{Conclusions}

This study of transforming a traditional school counseling program to online delivery shows the importance of meaningful learning experiences, opportunities for visual and 
interpersonal communication between students as well as the professor, and the most advanced technology programs and assistance to students. The results of this study show that students as educators have some insight into their own learning experiences that may contribute to the field of online learning. Online learning provides learning and professional opportunities for students that may not be available in a traditional classroom setting. Although, there is a need for improvement in personal interactions and advanced technology features, shared experiences and successes, along with innovation, will contribute to improved offerings in the future.

\section{REFERENCES}

[1] Graneheim, U. H., \& Lundman, B. (2004). Qualitative content analysis in nursing research: Concepts, procedures and measure to achieve trustworthiness, Nurse Education To- day, 24, 105-112

[2] Hiltz, S. R. \& Turoff, M. (2005). Education goes digital: The evolution of learning and the revolution in higher education. Communications of the ACM, 40(10), 59-64

[3] Mansour, B. E., \& Davison, M. M. (2007). Students' positive and negative experiences in hybrid and online classes. College Student Journal 41(1), 242-248

[4] Phillips, M., Hawkins, R., Lunsford, J. \& Sinclair-Pearson, A. (2004). Online student induction: A case study of the use of mass customization techniques. Open Learning, 19(2), 191-202

[5] Turner, J. E. \& Reed, P. A. (2006). Are you ready to provide instruction via interactive satellite delivery technology? The Quarterly Review of Distance Education, 7(4), 387-397

[6] Western Coorperative for Educational Telecommunications, (2004). Distance education: A consumer's guide. Western Cooperative for Educational Telecommunications. Retrieved December 6, 2010:

http://www.wcet.info/Resources/publications/conguide/Inter national, 47(4), 405-416 